\title{
Successive-station monthly streamflow prediction using different artificial neural network algorithms
}

\author{
A. Danandeh Mehr $\cdot$ E. Kahya $\cdot$ A. Şahin $\cdot$ \\ M. J. Nazemosadat
}

Received: 20 August 2013/Revised: 10 January 2014/Accepted: 5 May 2014/Published online: 21 May 2014

(C) Islamic Azad University (IAU) 2014

\begin{abstract}
In this study, applicability of successive-station prediction models, as a practical alternative to streamflow prediction in poor rain gauge catchments, has been investigated using monthly streamflow records of two successive stations on Çoruh River, Turkey. For this goal, at the first stage, based on eight different successive-station prediction scenarios, feed-forward back-propagation (FFBP) neural network algorithm has been applied as a brute search tool to find out the best scenario for the river. Then, two other artificial neural network (ANN) techniques, namely generalized regression neural network (GRNN) and radial basis function (RBF) algorithms, were used to generate two new ANN models for the selected scenario. Ultimately, a comparative performance study between the different algorithms has been performed using Nash-Sutcliffe efficiency, squared correlation coefficient, and root-meansquare error measures. The results indicated a promising role of successive-station methodology in monthly streamflow prediction. Performance analysis showed that only 1-month-lagged record of both stations was satisfactory to achieve accurate models with high-efficiency value. It is also found that the RBF network resulted in higher performance than FFBP and GRNN in our study domain.
\end{abstract}

A. Danandeh Mehr $(\varangle) \cdot$ E. Kahya

Hydraulics Division, Civil Engineering Department, Istanbul Technical University, 34469, Maslak, Istanbul, Turkey e-mail: danandeh@itu.edu.tr

\section{A. Şahin}

State Housing Development Administration (TOKI), Bilkent Plaza, B1, Blok 06800, Bilkent, Ankara, Turkey

M. J. Nazemosadat

Water Engineering Department, Climate Research Centre, College of Agriculture, Shiraz University, Shiraz, Iran
Keywords Artificial neural networks - Streamflow prediction - Successive stations - Ungauged catchments

\section{Introduction}

Modeling of streamflow process is important especially for planning, operating, and management of water resources. Accurate modeling also plays an important role in mitigating the impact of droughts and floods. Therefore, numerous hydrological models have been developed in order to simulate this complex process. A comprehensive classification of these models was presented by Nourani et al. (2007).

Because of low-density-gauging networks in mountainous regions, commonly used rainfall-runoff models are not applicable to predict streamflow in such regions. Therefore, it is necessary to develop new methods for the estimation of daily or monthly flows. Continuous streamflow records in such cases can provide systematic prediction models using time series analysis. In recent literature, due to advances in computing systems, application of artificial intelligence (AI) techniques for cross-station or singlestation daily or monthly streamflow prediction has been investigated, and successful results have been reported (Ochoa-Rivera et al. 2002; Kisi and Cigizoglu 2007; Kisi 2008; Demirel et al. 2009; Toprak et al. 2009; Besaw et al. 2010; Can et al. 2012).

Artificial neural networks (ANN) are sets of AI models inspired by animals' central nervous systems (in particular the brain) that can compute values from inputs by feeding information through the network. In recent years, ANN are increasingly used for prediction and pattern recognition problems in various fields of water and environmental science and technology such as total ozone forecasting 
(Bandyopadhyay and Chattopadhyay 2007), sea level prediction (Altunkaynak 2007, Imani et al. 2013), rainfallrunoff modeling (De Vos and Rientjes 2005, Kuok et al. 2010, Nourani et al. 2011), water quality prediction (Emamgholizadeh et al. 2013). A comprehensive literature review about the application of ANN in river forecasting was presented by Abrahart et al. (2012). The review shows inadequate comparative investigations of ANN-based streamflow prediction models. To the best of the author's knowledge, there is no comparative study about the application of different ANN algorithms in successivestation monthly streamflow prediction.

The main objectives of this study are (1) to discuss the applicability of successive-station prediction models as a practical alternative to streamflow prediction in poor rain gauge catchments and (2) for the first time, to compare the efficiency of different ANN algorithms for successivestation monthly streamflow prediction. However, the applicability of successive-station prediction process can be examined using conventional time series analysis methods.

For this aim, at the first stage, we put forward eight different successive-station prediction scenarios, based upon feed-forward back-propagation neural network algorithm (FFBP). In successive-station prediction scenarios, streamflow at a target station is assumed to be a function of previous streamflow records of one upper station and/or both target and the upper stations. Therefore, instead of antecedent records of only target station (single-station models) or different points stations (cross-station models), we developed different monthly lag-time scenarios between two successive stations on a perennial river located in Turkey, and then, we evaluated them as candidates for monthly streamflow prediction model of the river.

In the second stage, two other ANN techniques, generalized regression neural networks (GRNN) and radial basis function (RBF) neural networks, were utilized to remodel the best FFBP-based scenario. Ultimately, a comparative performance study between the developed models has been performed using Nash-Sutcliffe efficiency, squared correlation coefficient, and root-meansquare error measures. Such a comparison between different ANN models has also been investigated by Kisi and Cigizoglu (2007), but they considered only daily streamflow on a single station.

Study area and data

Our study area is the Çoruh River, a perennial river located in eastern Black Sea region, Turkey (Fig. 1). The river catchment approximately covers $20,000 \mathrm{~km}^{2}$, which is about $2.53 \%$ territory of Turkey. The river springs from Mescit Mountains in Bayburt and reaches the Black Sea in
Batum City of Georgia, after a course of $431 \mathrm{~km}$. Mean annual flow of the river before leaving Turkey's border is about $200 \mathrm{~m}^{3} / \mathrm{s}$. The locations of two successive gauging stations, stations 2322 and 2315, with 40 kilometers distance, used in this study are shown in Fig. 1 and their monthly streamflow time series at 29-year period (1972-2000) is presented in Fig. 2. Table 1 represents the statistical characteristics of our applied data.

Çoruh is a shared river between Turkey and Georgia. Monthly streamflow prediction at the lower reach of the river, trans-boundary reach, will help both countries' water recourses managers make suitable decisions in dry or wet spells or to resolve probable conflicts about sharing of river water.

\section{Materials and methods}

Overview of FFBP, GRNN, and RBF algorithms

Artificial neural networks are flexible modeling methods in which someone uses input and output data sets to find out the system attitude. In fact, they are nothing more than complex version of regression models. FFBP networks are probably the most popular ANN in engineering problems (Tahershamsi et al. 2012; Krishna 2013), which considered as general nonlinear approximations (Hornik et al. 1989). The primary goal of this algorithm was to minimize the estimation error by searching for a set of connection weights that cause the network to produce outputs closer to the targets. They are typically composed of three parts: (a) input layer including a number of input nodes, (b) one or more hidden layers, and (c) a number of output layer nodes. The number of hidden layers and nodes in them are two of the design parameters of FFBP. In the FFBP algorithm, any input node will be multiplied by a proper weight initially and then will be added by a constant value, which is called bias, and finally will be entered to a predefined activation functions. The explicit expression for an output value of a FFBP network is given by Nourani et al. (2013).

Radial basis function is a variant of ANN that uses radial basis functions, real-valued functions whose value depends only on the distance from the origin, as activation functions. RBF networks have not been used extensively in environmental studies except a few researchers such as Azmathullah et al. (2005), Bateni et al. (2007) and Tahershamsi et al. (2012). A typical RBF network has a feedforward structure consists of an input layer, a hidden layer with a radial basis activation function, and a linear output layer. The hidden layer node calculates the Euclidean distance between the center of function and the network input layer and then passes the result to the radial basis 


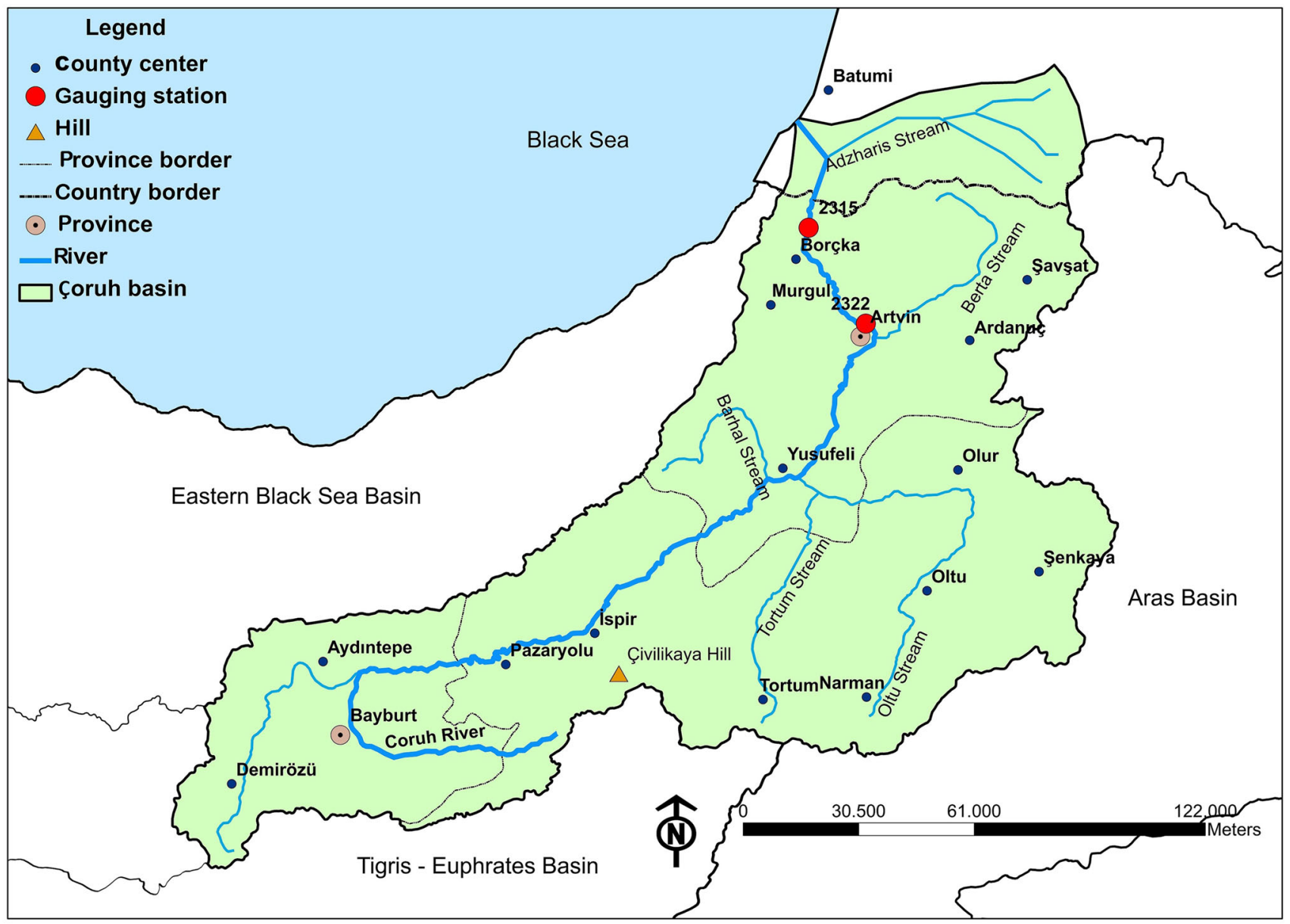

Fig. 1 Location of study area (Çoruh River Catchment)

Fig. 2 Observed streamflow at the 29-year period

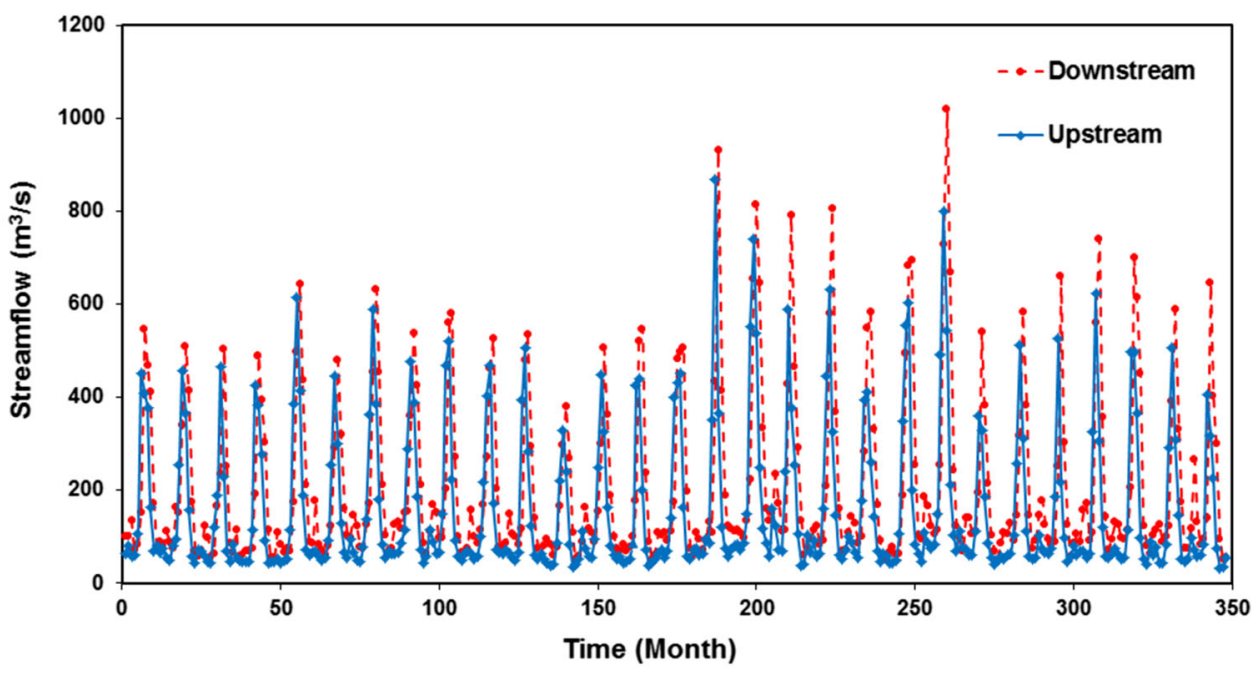

function. Thus, the hidden layer performs a fixed nonlinear transformation, which maps the input space onto a new space. The output layer implements a weighted sum of hidden layer outputs. In order to use RBF, we need to specify the number of layers, a radial activation function, and a criterion for network training. Detailed information on the application of RBF networks on streamflow prediction has been provided by Kisi (2008). 
Table 1 The monthly statistical parameters of observed streamflow data

\begin{tabular}{llllll}
\hline Statistical parameter & \multicolumn{2}{l}{ Station } & & \\
\cline { 2 - 3 } & \multicolumn{2}{l}{ Upstream $(2322)$} & & \multicolumn{2}{l}{ Downstream (2315) } \\
\cline { 2 - 3 } \cline { 5 - 6 } \cline { 5 - 6 } & Raw & Normalized & & Raw & Normalized \\
\hline Number of data $(X)$ & 348 & 348 & & 348 & 348 \\
$X_{\text {max }}\left(\mathrm{m}^{3} / \mathrm{s}\right)$ & 867.4 & 0.9321 & & $1,018.2$ & 0.9404 \\
$X_{\min }\left(\mathrm{m}^{3} / \mathrm{s}\right)$ & 33.5 & 0.1321 & & 48.9 & 0.1404 \\
$X_{\text {mean }}\left(\mathrm{m}^{3} / \mathrm{s}\right)$ & 158.6 & 0.2522 & & 207.1 & 0.2709 \\
$\begin{array}{c}\text { Standard deviation } \\
\left(\mathrm{m}^{3} / \mathrm{s}\right)\end{array}$ & 159.1 & 0.1526 & & 184.4 & 0.1522 \\
$\begin{array}{c}\text { Coefficient of } \\
\text { skewness }\end{array}$ & 1.7271 & 1.7271 & & 1.7001 & 1.7001 \\
\hline
\end{tabular}

Table 2 Statistical parameters of subsets

\begin{tabular}{llll}
\hline Parameters & Entire data & Training set & Validation set \\
\hline Number of data $(X)$ & 348 & 244 & 104 \\
$X_{\max }\left(\mathrm{m}^{3} / \mathrm{s}\right)$ & 1,018 & 930 & 1,018 \\
$X_{\min }\left(\mathrm{m}^{3} / \mathrm{s}\right)$ & 33.5 & 36 & 48 \\
$X_{\text {mean }}\left(\mathrm{m}^{3} / \mathrm{s}\right)$ & 158.6 & 158 & 223 \\
Standard deviation $\left(\mathrm{m}^{3} / \mathrm{s}\right)$ & 159.1 & 156 & 204 \\
Coefficient of skewness & 1.7271 & 1.71 & 1.71
\end{tabular}

The GRNN is a kind of radial basis networks that only uses training data with $\mathrm{BP}$ algorithm to derive estimation function. It typically consists of four layers: input layer, pattern layer, summation layer, and output layer. The number of input units in the first layer is equal to the total number of parameters. The first layer is fully connected to the pattern layer, where each unit represents a training pattern, and its output is a measure of the distance of the input from the stored patterns. Each pattern layer is connected to the two neurons (i.e., S-summation neuron and D-summation neuron) in the summation layer. The S-summation neuron computes the sum of the weighted outputs of the pattern layer, whereas the D-summation neuron calculates the unweighted outputs of the pattern neurons. The basics of the GRNN algorithm can be obtained from the literature (Specht 1991).

\section{Normalization and efficiency criteria}

As it mentioned previously, our data record is composed of 348 observations of the monthly streamflow at each station. The first $70 \%$ and the last $30 \%$ of observations were selected for training and validation of all networks, respectively. Therefore, the entire data set were divided into two subsets. The statistical parameters for each set and the entire data set are presented in Table 2.
Prior to the training of our ANN models, the normalization was applied for the data. Normalization is essential to ANN which makes the data dimensionless and confines them within a certain range. The range of input data within 0.0 and 1.0 has been used herein through dividing the observation data by the maximum observed data. After training, the model that yields the best results in terms of Nash-Sutcliffe coefficient (NS), root-mean-squared error (RMSE) is selected as the most efficient model. The strength of the linear relationship between the prediction and observations is also measured by the $r$-square value $\left(R^{2}\right)$. NS is a normalized indicator of the model's ability to predict about the $1: 1$ line between observed and predicted data (Eq. 1). RMSE, Eq. 2, measures the root average of the squares of the errors. $R^{2}$, Eq. 3, returns the square of the Pearson product moment correlation coefficient that can be interpreted as the proportion of the variance in prediction to the variance in observation.

$\mathrm{NS}=1-\frac{\sum_{i=1}^{n}\left(X_{i}^{\mathrm{obs}}-X_{i}^{\mathrm{pre}}\right)^{2}}{\sum_{i=1}^{n}\left(X_{i}^{\mathrm{obs}}-X_{\text {mean }}^{\mathrm{obs}}\right)^{2}}$
$\mathrm{RMSE}=\sqrt{\frac{\sum_{i=1}^{n}\left(X_{i}^{\mathrm{obs}}-X_{i}^{\mathrm{pre}}\right)^{2}}{n}}$

$R^{2}=\frac{\left(\sum_{i=1}^{n}\left(X_{i}^{\mathrm{obs}}-X_{\text {mean }}^{\mathrm{obs}}\right)\left(X_{i}^{\mathrm{pre}}-X_{\text {mean }}^{\mathrm{pre}}\right)\right)^{2}}{\sum_{i=1}^{n}\left(X_{i}^{\mathrm{obs}}-X_{\text {mean }}^{\mathrm{obs}}\right)^{2} \sum_{i=1}^{n}\left(X_{i}^{\mathrm{pre}}-X_{\text {mean }}^{\mathrm{pre}}\right)^{2}}$

where $X_{i}^{\mathrm{obs}}=$ observed value of $X, X_{i}^{\mathrm{pre}}=$ predicted value, $X_{\text {mean }}^{\text {obs }}=$ mean value of observed data, and $n=$ number of observed data.

Obviously, a high value for NS and small values for RMSE indicate high efficiency of the corresponding ANN model. The ideal value of the RMSE is zero in which case the value of NS efficiency index is unity (Sajikumar and Thandaveswara 1999). The ANN model predictions are linearly correlated with observations if the model provides higher value for $R^{2}$ (up to 1). More information about the differences between the NS and $R^{2}$ measures can be found in the "Reply to comment" presented by Nourani (2010).

\section{FFBP modeling}

Considering the monthly streamflow time series of the Çoruh River in station 2315 at downstream and station 2322 at upstream, eight prediction scenarios (see Table 3, models (1) to (8)) were generated by lag 1 and 
Table 3 The MSE, RMSE and NS of evaluated FFBP models

\begin{tabular}{|c|c|c|c|c|c|c|}
\hline \multirow[t]{2}{*}{ Model number } & \multirow[t]{2}{*}{ Prediction scenario $^{a}$} & \multirow{2}{*}{$\begin{array}{l}\text { Nodes in } \\
\text { hidden layer }^{\text {b }}\end{array}$} & \multicolumn{4}{|c|}{$\operatorname{MSE}\left(* 10^{-2}\right)$} \\
\hline & & & Training & Validation & RMSE $^{\mathrm{c}}$ & $\mathrm{NS}^{\mathrm{c}}$ \\
\hline 1 & $D_{t}=f\left(D_{t-1}\right)$ & 3 & 1.351 & 1.006 & 0.114 & 0.440 \\
\hline 2 & $D_{t}=f\left(U_{t}\right)$ & 4 & 1.048 & 0.972 & 0.102 & 0.547 \\
\hline 3 & $D_{t}=f\left(D_{t-1}, U_{t}\right)$ & 5 & 0.2876 & 0.2046 & 0.053 & 0.879 \\
\hline 4 & $D_{t}=f\left(U_{t-1}, D_{t-1}\right)$ & 8 & 0.0590 & 0.0877 & 0.025 & 0.972 \\
\hline 5 & $D_{t}=f\left(U_{t-1}, U_{t}, D_{t-1}\right)$ & 3 & 0.0500 & 0.0103 & 0.025 & 0.972 \\
\hline 6 & $D_{t}=f\left(U_{t-2}, U_{t-1}, D_{t-2}, D_{t-1}\right)$ & 8 & 0.0438 & 0.0168 & 0.025 & 0.973 \\
\hline 7 & $D_{t}=f\left(U_{t-2}, U_{t-1}, D_{t-2}, D_{t-1}\right)$ & 7 & 0.0403 & 0.0399 & 0.021 & 0.980 \\
\hline 8 & $D_{t}=f\left(U_{t-2}, U_{t-1}, U_{t}, D_{t-2}, D_{t-1}\right)$ & 9 & 0.0388 & 0.0419 & 0.022 & 0.979 \\
\hline
\end{tabular}

lag 2 processes and assumed as monthly streamflow prediction candidates at downstream (target) station. These time series were then entered into a three-layer FFBP-ANN model as a brute search tool to find out the best scenario for streamflow prediction at the target station. For this aim, several three-layer FFBP networks with sigmoid transfer function in hidden layer and linear transfer function in output layer have been employed. It has been proved that three-layer FFBP networks are satisfied for the forecasting and simulating in any engineering problem (ASCE 2000; Chau et al. 2005; Nourani et al. 2008; Rezaeianzadeh et al. 2013a). The satisfactory application of the sigmoid and linear transfer functions in hidden and output layers, respectively, for streamflow prediction was also extensively reported (e.g., Chang et al. 2007; Krishna 2013; Rezaeianzadeh et al. 2013b). Following the definition of modeling structures, a program code including Levenberg-Marquardt (LM) algorithm was written in the MATLAB $^{\circledR}$ software for carrying out the training and validation process. The LM is one of the Newtonian optimization techniques and more powerful than conventional gradient descent techniques (Kisi and Cigizoglu 2007), which is widely used in FFBPs (e.g., Haykin 1999; De Vos and Rientjes 2005; Chau et al. 2006; Cannas et al. 2006; Kisi 2010; Danandeh Mehr et al. 2013).

In our simulations, all proposed models possess fixed input nodes that vary from 1 to 5 for models (1) to (8). A single hidden layer with nodes varies from 1 to 10 and only one node in the output layer. Determination of optimum number of neurons in hidden layer is an important aspect of an efficient network. A trial and error approach is adopted to select the optimum number of neurons in the hidden layer. The sum of mean square errors of both training and validation steps in each trial was used as a criterion for selecting the optimal number of neurons in hidden layer. No great improvement in model performance was found when the number of hidden neurons was increased from a threshold, which is similar to the experience reported by Abrahart and See (2000) and Nourani et al. (2011). The NS and RMSE values have been used to compare the performance of different scenarios in order to select the best one.

\section{GRNN and RBF modeling}

In the second part of the study, two different program codes were written in the MATLAB ${ }^{\circledR}$ to generate different neural structures for the chosen scenario (i.e., Model (4)). In GRNN simulation, the same period of training and validation with FFBP has been applied. However, in RBF simulation, only training part of the data was used. Determination of optimum value of spread parameter in both GRNN and RBF is one of the important aspects of an efficient network designing in this phase. We employed a trial and error approach to select the optimum value of this parameter. The RMSE and NS value of validation step in each trial is used as a criterion for selecting the optimal value of spread parameter. In order to optimize RBF model, different number of nodes in the hidden layer (RBF centers) were also examined in each trial. For this goal, the utilized training program adds neurons to the hidden layer of a RBF network until it meets the specified mean squared error or maximum number of neurons. In order to make a fare comparison to FFBP, the maximum number of hidden layer neurons within RBF networks was also confined to 10 as well as upper threshold of FFBP networks. 

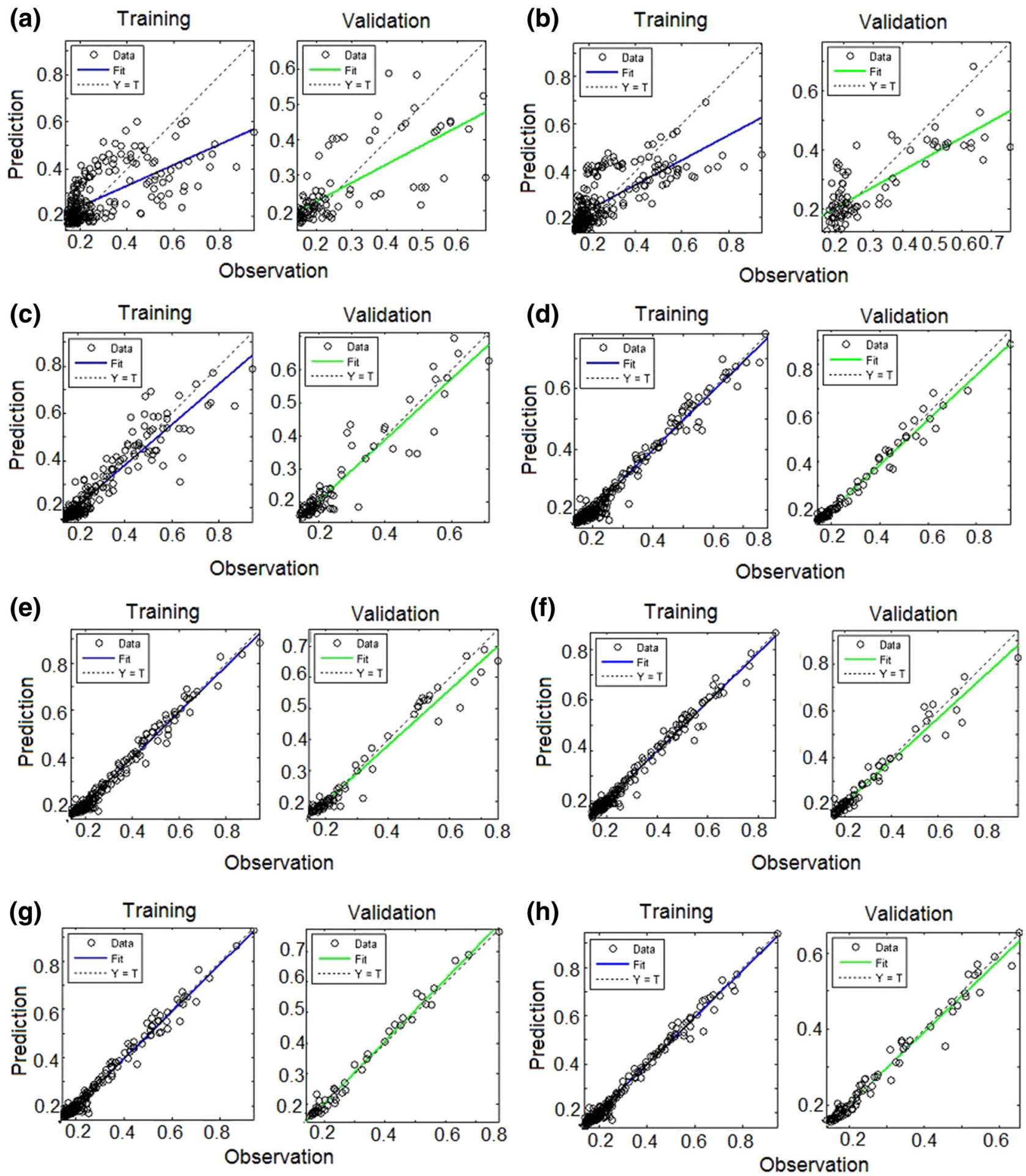

Fig. 3 Comparison of dimensionless predicted streamflow for the calibrations and validations by different models: a model 1 , b model 2 , c model 3, d model 4, e model 5 , f model 6 , $\mathbf{g}$ model $7, \mathbf{h}$ model 8

\section{Results and discussion}

Table 3 presents the results of the best ANN structure for each scenario trained and validated by FFBP algorithm.
Scatterplots of predicted and observed streamflow at target station for each scenario have also been illustrated in Fig. 3. The tabulated results and Fig. 3 indicate that models (1) and (2) resulted in the lowest achieved performance 

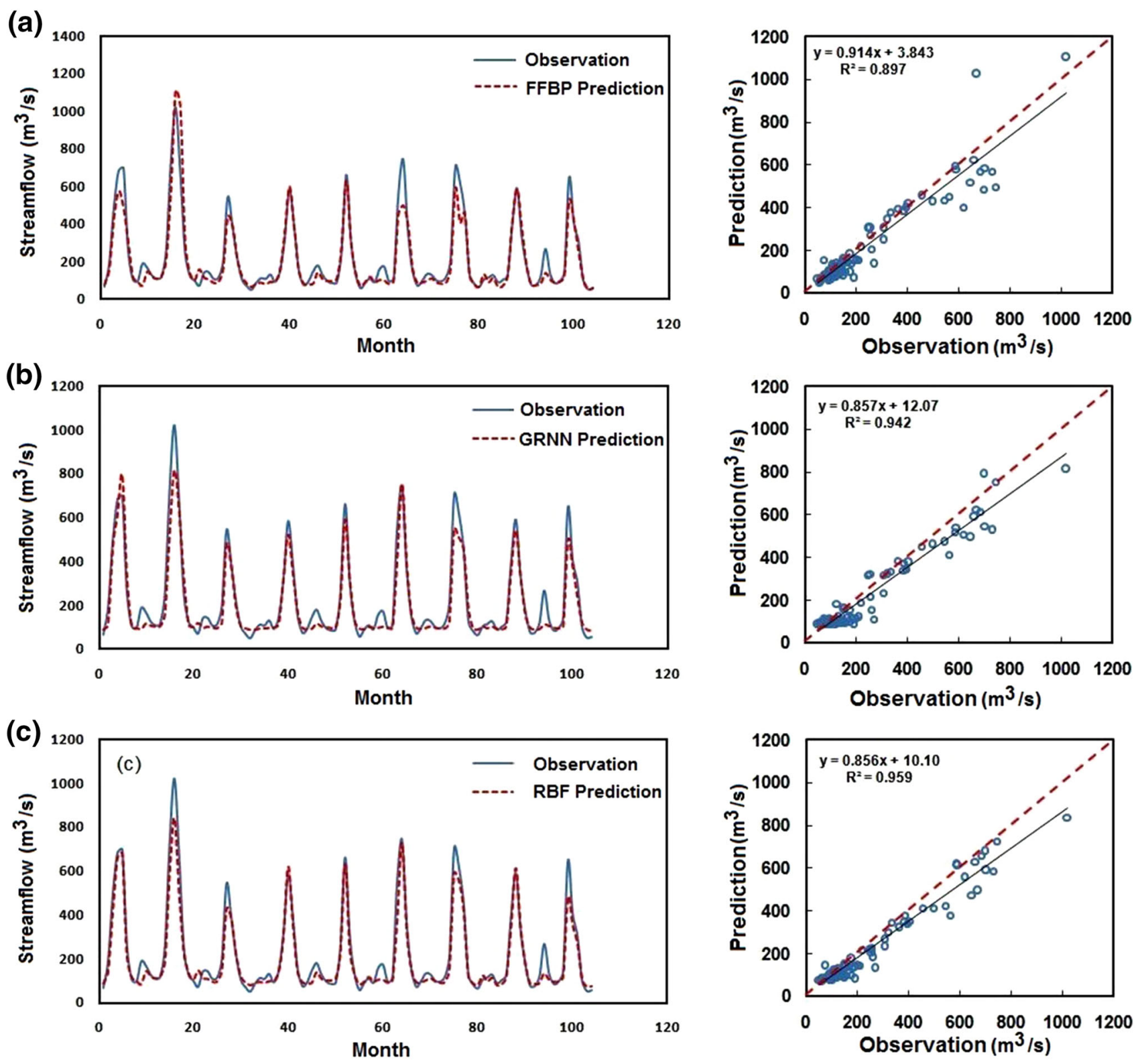

Fig. 4 Observed and predicted monthly streamflow by of a FFBP, b GRNN, and $\mathbf{c}$ RBF techniques

level. The reason behind is obviously related to choice of only one variable in input layer. The first combination of upstream and downstream flow models, model (3), demonstrated a dramatic improvement in the performance levels. The reason lies under the fact that the existing subbasins between the successive stations may have considerable physical effects (i.e., increasing drainage area) on the flow regime in the downstream station. This is the reason why we instantly keep downstream flow at time $(t-1), D_{t-1}$, in constructing models (4) to (8). These models represent five effective FFBP structures with high performance levels, which all appeared to be so close to each other.

Models (4) and (5) use both flows at time $(t-1)$ in both downstream and upstream stations, $D_{t-1}$ and $U_{t-1}$, respectively; however, Model (5) involves current time flow in upstream station, $U_{t}$, as additional input variable. Addition of one more variable into the input layer of Model (5) interestingly did not result in noticeable change in the model performance, whereas it decreases the number of neurons in the hidden layer. The effect of time lags up to two month earlier has been shown in the 
Table 4 Performance comparison of different ANN techniques at validation period

\begin{tabular}{|c|c|c|c|c|c|c|c|c|}
\hline \multicolumn{3}{|l|}{ FFBP } & \multicolumn{3}{|l|}{$\mathrm{RBF}$} & \multicolumn{3}{|c|}{ GRNN } \\
\hline$\overline{R^{2}}$ & RMSE & NS & $\overline{R^{2}}$ & RMSE & NS & $R^{2}$ & RMSE & NS \\
\hline 0.897 & 66.93 & 0.89 & 0.959 & 51.4 & 0.94 & 0.942 & 55.61 & 0.93 \\
\hline
\end{tabular}

remaining three different scenarios (i.e., models (6) to (8)) as having no change or negligible improvement in the individual model performance level. Hence, 1-month lag has been seemed to be sufficient for successivestation monthly streamflow prediction at our study reach. This result is entirely consistent with the experiments of Kisi (2008) at cross-section monthly streamflow prediction. It implies a promising role for successive-station methodology in monthly streamflow prediction. Therefore, Model (4) is accepted as the best scenario of FFBP approach in order to be subject for remodeling by RBF and GRNN algorithms in the second step of the research.

The best structured GRNN and RBF streamflow prediction results, as well as FFBP, for Model (4) in comparison with corresponding observations for the validation period are depicted in Fig. 4. The figure shows that all ANN predictions are parallel to the observed time series; however, there are underestimations for some peaks. Dividing all observed data by their maximum value, the applied normalization process can be a reason behind this. Another reason may be availability of a small number of training subsets for peak flows. In order to further assessment of the proposed ANN models, scatterplots of the predicted streamflow versus the actual observations are also presented in Fig. 4, and the corresponding performance levels are compared in Table 4. The highest NS and $R^{2}$ value, as well as the lowest RMSE, was obtained for RBF modeling. It can also be inferred that both RBP and GRNN algorithms have higher quality than FFBP in monthly streamflow prediction; however, RBF method resulted in the highest performance outcomes.

In front of proposed ANN-based successive-station streamflow prediction modeling advantages, the training and validation process for each model exposed some disadvantages. It has been observed that after each FFBP trail, different prediction values are obtained with the same network structure, resulting in different performance level. This drawback is mainly due to the random assignment of initial weights in the beginning of each trial. In addition, the performance of FFBP, RBF, and GRNN networks are critically depended on the chosen number of hidden nodes, RBF centers, and spread constant, respectively. Some of the training trials showed that random selection of these parameters may provide unsatisfactory results. Therefore, in order to optimize the mentioned parameters, implementation of an optimization technique in parallel with training algorithm is inevitable. We employed a brute search method among the plausible ranges for the parameters. The results showed that the selection of the number of hidden neurons in range of 3 through 9, RBF centers equal to 1.0, and spread constant equals to 0.05 can result in highest performance for FFBP, RBF, and GRNN models, respectively. Hence, selections of such parameter values are suggested for similar time series. It is also important to note that spread constant values higher than 0.5 in GRNN produced too smooth approximation functions that were not able to capture extreme streamflow.

Another noticeable result of this research is the higher capability of the FFBP algorithm in the prediction of the low $\left(D_{t}<200 \mathrm{~m}^{3} / \mathrm{s}\right)$ flows (see Fig. 3). In contrast, inability of FFBP algorithm to predict low monthly streamflow, due to generation of negative values, has already been reported by Kisi (2008). The reason behind these contradictory conclusions might be related to the difference between the flow regime of the investigated rivers. It can be inferred that the existence of zero values in training subsets of intermittent rivers (as existed in Kisi's experience) can mislead FFBP algorithms. Therefore, FFBP algorithm might be more reliable for drought or dry spells predictions in perennial rivers' catchments.

\section{Conclusion}

In this study, eight different streamflow prediction models based upon monthly data of two successive stations have been evaluated as a streamflow prediction scenarios for a sparse rain gaged reach of Çoruh River in Turkey. Prediction scenarios were modeled by FFBP algorithm and compared with each other. The FFBP algorithm showed that only 1-month-lagged record of successive stations is satisfactory to achieve an accurate monthly streamflow prediction model with more than 0.97 NS value. Therefore, successive-station prediction methodology assessed as an appropriate alternative for monthly streamflow prediction in the poorly gaged reach of Çoruh River catchments. 
In the second phase of the study, GRNN and RBF algorithms for the first time were applied to 1-month-ahead successive-station streamflow prediction, and the results were compared with those of FFBP. According to the performances analysis results, the RBF network is found to be superior to GRNN and FFBP techniques in successivestation monthly streamflow prediction which is consistent with the results of Kisi and Cigizoglu (2007) in singlestation daily streamflow forecasting experiment. Higher performance of FFBP in low-flow prediction indicated its ability for drought or dry spells prediction goals in perennial rivers' catchment.

This study considered only ANN-based modeling approach and used data from one catchment. Further studies using different methods of time series modeling as well as more data from different areas may be required to strengthen our conclusions.

Acknowledgments The authors would like to thank Prof. H. Kerem Cigizoglu for his helpful guides during this research.

\section{References}

Abrahart RJ, See L (2000) Comparing neural network (NN) and auto regressive moving average (ARMA) techniques for the provision of continuous river flow forecasts in two contrasting catchments. Hydrol Process 14:2157-2172

Abrahart RJ, Anctil F, Coulibaly P, Dawson CW, Mount NJ, See LM, Shamseldin AY, Solomatine DP, Toth E, Wilby RL (2012) Two decades of anarchy? Emerging themes and outstanding challenges for neural network modelling of surface hydrology. Prog Phys Geogr 36(4):480-513

Altunkaynak A (2007) Forecasting surface water level fluctuations of Lake Van by artificial neural networks. Water Resour Manag 21:399-408

ASCE Task committee (2000) Artificial neural networks in hydrology: hydrologic applications. J Hydrol Eng 5(2):124-137

Azmathullah HM, Deo MC, Deolalikar PB et al (2005) Neural network for estimation of scour downstream of a ski-jump bucket. J Hydraul Eng 131(10):898-908

Bandyopadhyay G, Chattopadhyay S (2007) Single hidden layer artificial neural network models versus multiple linear regression model in forecasting the time series of total ozone. Int J Environ Sci Technol 4:141-150

Bateni SM, Borghei SM, Jeng DS (2007) Neural network and neurofuzzy assessments for scour depth around bridge piers. Eng Appl Artif Intell 20:401-414

Besaw LE, Rizzo DM, Bierman PR, Hackett WR (2010) Advances in ungauged streamflow prediction using artificial neural networks. J Hydrol 386:27-37

Can I, Tosunogulu F, Kahya E (2012) Daily streamflow modelling using autoregressive moving average and artificial neural networks models: case study of Çoruh basin, Turkey. Water Environ J 26:567-576

Cannas B, Fanni A, See L, Sias G (2006) Data preprocessing for river flow forecasting using neural networks: wavelet transforms and data partitioning. Phys Chem Earth, PartsA/B/C 31(18): $1164-1171$
Chang FJ, Chiang YM, Chang LC (2007) Multi-step-ahead neural networks for flood forecasting. Hydrol Sci J 52(1):114-130

Chau KW, Wu CL, Li YS (2005) Comparison of several flood forecasting models in Yangtze River. $J$ Hydrol Eng 10(6):485-491

Danandeh Mehr A, Kahya E, Olyaie E (2013) Streamflow prediction using linear genetic programming in comparison with a neurowavelet technique. J Hydrol 505:240-249

De Vos NJ, Rientjes THM (2005) Constraints of artificial neural networks for rainfall-runoff modeling: trade-offs in hydrological state representation and model evaluation. Hydrol Earth Syst Sci 9:111-126

Demirel MC, Venancio A, Kahya E (2009) Flow forecast by SWAT model and ANN in Pracana basin, Portugal. Adv Eng Softw 40(7):467-473

Emamgholizadeh S, Kashi H, Marofpoor I, Zalaghi E (2013) Prediction of water quality parameters of Karoon River (Iran) by artificial intelligence-based models. Int $\mathrm{J}$ Environ Sci Technol. doi:10.1007/s13762-013-0378-x

Hornik K, Stinchcombe M, White M (1989) Multi-layer feed forward networks are universal approximators. Neural Netw 2:359-366

Imani M, You RJ, Kuo CY (2013) Caspian Sea level prediction using satellite altimetry by artificial neural networks. Int J Environ Sci Technol. doi:10.1007/s13762-013-0287-z

Kisi O (2008) Stream flow forecasting using neuro-wavelet technique. Hydrol Process 22:4142-4152

Kisi O (2010) Wavelet regression model for short-term streamflow forecasting. J Hydrol 389:344-353

Kisi O, Cigizoglu HK (2007) Comparison of different ANN techniques in river flow prediction. Civ Eng Environ Syst 24:211-231

Krishna B (2013) Comparison of wavelet based ANN and regression models for reservoir inflow forecasting. J Hydrol Eng. doi:10. 1061/(ASCE)HE.1943-5584.0000892

Kuok KK, Harun S, Shamsuddin SM (2010) Particle swarm optimization feedforward neural network for modeling runoff. Int J Environ Sci Technol 7(1):67-78

Nourani V (2010) Reply to comment on "Nourani V, Mogaddam AA, Nadiri AO. 2008. An ANN based model for spatiotemporal groundwater level forecasting. Hydrol Process 22: 5054-5066". Hydrol Process 24:370-371

Nourani V, Monadjemi P, Singh VP (2007) Liquid analogue model for laboratory simulation of rainfall-runoff process. J Hydrol Eng 12(3):246-255

Nourani V, Mogaddam AA, Nadiri AO (2008) An ANN based model for spatiotemporal groundwater level forecasting. Hydrol Process 22:5054-5066

Nourani V, Kisi Ö, Komasi M (2011) Two hybrid artificial intelligence approaches for modelling rainfall-runoff process. J Hydrol 402:41-59

Nourani V, Hosseini Baghanam A, Adamowski J, Gebremichael M (2013) Using self-organizing maps and wavelet transforms for space-time pre-processing of satellite precipitation and runoff data in neural network based rainfall-runoff modeling. J Hydrol 476:228-243

Ochoa-Rivera JC, Garcia-Bartual R, Andreu J (2002) Multivariate synthetic stream flow generation using a hybrid model based on artificial neural networks. Hydrol Earth Syst Sci 6(4):641-654

Rezaeianzadeh M, Stein A, Tabari H, Abghari H, Jalalkamali N, Hosseinipour EZ, Singh VP (2013a) Assessment of a conceptual hydrological model and artificial neural networks for daily outflows forecasting. Int $\mathrm{J}$ Environ Sci Technol 10(6):1181-1192 
Rezaeianzadeh M, Tabari H, Abghari H (2013b) Prediction of monthly discharge volume by different artificial neural network algorithms in semi-arid regions. Arab J Geosci 6:2529-2537

Specht DF (1991) A general regression neural network. IEEE Trans Neural Netw 2(6):568-576

Tahershamsi A, Majdzade Tabatabai MR, Shirkhani R (2012) An evaluation model of artificial neural network to predict stable width in gravel Bed Rivers. Int J Environ Sci Technol 9:333-342
Toprak ZF, Eris E, Agiralioglu N, Cigizoglu HK, Yilmaz L, Aksoy K, Coskun HG, Andic G, Alganci U (2009) Modeling monthly mean flow in a poorly gauged basin by fuzzy logic. Clean-Soil, Air. Water 37(7):555-564 